\title{
INDÚSTRIA CULTURAL E SEMIFORMAÇÃO: A ATUALIDADE DA EDUCAÇÃO APÓS AUSCHWITZ
}

\author{
Antônio Álvaro Zuim*
}

\begin{abstract}
RESUMO
Tem-se como objetivo argumentar que as considerações de Theodor W. Adorno, sobre a possibilidade de reincidência da barbárie de Auschwitz, devem ser revitalizadas. Parte-se do pressuposto de que essas considerações são fundamentais para que se possa refletir a respeito do modo como o atual desenvolvimento tecnológico da indústria cultural estimula a revitalização da semiformação e, portanto, o reaparecimento de um clima propício ao retorno da barbárie, na forma da reprodução do preconceito delirante, da frieza, da dessensibilização e sadomasoquismo dentro e fora das escolas.
\end{abstract}

Palavras-chave: Educação após Auschwitz. Semiformação. Indústria Cultural. Theodor W. Adorno. Teoria Crítica.

\begin{abstract}
The objective of this article is to discuss Theodor W. Adorno's considerations about the possibility of reissue the barbarism of Auschwitz should be revived. Starting from the presumption that they are fundamental for reflecting on the subject in view of the technological development nowadays of culture industry stimulating the revival of Semi-edication and, therefore, the return of barbarism in the form of reproduction of

\footnotetext{
* Professor-Associado do Departamento de Educação e do Programa de PósGraduação em Educação da Universidade Federal de São Carlos. Doutor em Educação pela Universidade de Campinas (UNICAMP), com estágio doutoral na Universidade Johann Wolfgang Goethe em Frankfurt por meio do convênio CAPES-DAAD. PósDoutor em Filosofia da Educação pela Universidade de Leipzig, Alemanha.

E-mail:dazu@ufscar.br
} 
the delirant prejudice, of the coldness, of the de-sensitization and sadomasochism inside and outside Schools.

Keywords: Education after Auschwitz. Semi-education. Cultural Industry. Theodor W. Adorno. Critical Theory.

\section{Introdução}

Mais de quarenta anos após a palestra: "Educação após Auschwitz", o apelo de seu autor, Theodor W. Adorno, permanece extremamente atual: "para a educação, a exigência que Auschwitz não se repita é primordial" (ADORNO, 1971, p. 88), assim como o inconformismo do pensador frankfurtiano que não conseguia entender quão pouca atenção as barbáries, cometidas no campo de concentração de Auschwitz durante a Segunda Guerra Mundial, haviam recebido por parte daqueles preocupados com o desenvolvimento do processo educacional/formativo. De fato, cada vez que uma atrocidade era praticada nos campos de concentração, quer seja na forma humilhante de violência simbólica, quer seja no assassinato e nas mutilações dos corpos de judeus, ciganos, intelectuais, homossexuais, etc., negava-se qualquer possibilidade de humanização fundamentada em alicerces culturais, cujas bases não se revelaram, com o passar do tempo, tão firmes assim. Ou seja, o fato de determinados indivíduos serem considerados cultos, em virtude da facilidade de apreensão de certos conteúdos, não significava necessariamente que fossem mais humanos, haja vista o famoso exemplo dos oficiais nazistas de Auschwitz que matavam os prisioneiros ao som de música clássica.

O paradoxo presente entre a possibilidade da existência de uma vida mais humana - que cada produto cultural, tal como a obra de música clássica, mediatiza em si - e a realização imediata do desejo de assassinar necessita ser compreendido de acordo com as características do processo histórico em que tal fracasso educacional/formativo se manifesta. Foram vários os pensadores que, premonitoriamente, conseguiram captar os sinais de recrudescimento de um clima cultural totalitário, tal como no caso de Freud e suas ponderações sobre o mal-estar na cultura poucos anos antes da consolidação da hegemonia nazista. Por outro lado, há 
uma série de autores, tais como Adorno e Horkheimer, cujos textos versaram sobre o entendimento das causas psicossociais do antisemitismo (ADORNO; HORKHEIMER, 1986). Tem-se como objetivo argumentar que as considerações de Theodor W. Adorno, sobre a possibilidade de reincidência da barbárie de Auschwitz, devem ser revitalizadas. Parte-se do pressuposto de que essas considerações são fundamentais para que se possa refletir a respeito do modo como o atual desenvolvimento tecnológico da indústria cultural estimula a revitalização da semiformação e, portanto, o reaparecimento de um clima propício ao retorno da barbárie, na forma de reprodução do preconceito delirante, da frieza, da dessensibilização e do sadomasoquismo dentro e fora das escolas.

\section{A Semiformação e a falsa Projeção como Estrato subjetivo do Pensamento autoritário}

É difícil afirmar categoricamente quais foram os momentos na história da humanidade que poderiam ser distinguidos como aqueles em que seus partícipes atingiram o ápice do prazer sádico de maltratar e, até mesmo, acabar com vida alheia, uma vez que o ser humano parece desenvolver, historicamente, formas cada vez mais sofisticadas de concretizar tal prazer. Mas aquilo que aconteceu nos campos de concentração durante a segunda guerra mundial certamente pode ser identificado como um desses momentos. Os ecos dos assassinatos, das mutilações, das violações e das humilhações de milhões de pessoas ainda ressoam com muita força e incitam a reflexão de como o ser humano pôde chegar a tal ponto. Daí o sugestivo título do livro de um dos sobreviventes dos horrores cometidos em Auschwitz, a saber, Primo Levi: "É isto um homem?"

São famosos os relatórios nazistas, tais como os que se encontram no museu judaico de Frankfurt am Main, na Alemanha, cujos cálculos se referem à quantidade ideal de peças que poderiam ser transportadas nos vagões dos trens até os campos de concentração. ${ }^{1} \mathrm{O}$ "detalhe" é que as

\footnotetext{
${ }^{1} \mathrm{Na}$ palestra para a rádio de Hessen, proferida em abril de 1965 e que deu origem ao texto: "Educação após Auschwitz", Adorno relacionou a fetichização da tecnologia com o fato de que, durante o nazismo, se pensou em transportar o mais rapidamente
} 
peças descritas eram seres humanos. Primo Levi vivenciou uma situação dessa e a descreveu da seguinte forma:

Com absurda precisão à qual nos acostumaríamos mais tarde, os alemães fizeram a chamada. Por fim, - Wieviel Stuck? (quantas peças?) - perguntou o sargento, e o cabo, batendo continência, respondeu que as "peças" eram seiscentas e cinqüenta, e que tudo estava em ordem. Embarcaram-nos nos ônibus e fomos levados para a estação de Capri. Lá nos esperavam o trem e a escolta para a viagem. Foi lá que recebemos os primeiros socos; e a coisa foi tão nova e insensata que não chegamos a sentir dor, nem no corpo e nem na alma. Apenas um estupor profundo: como é que, sem raiva, pode-se socar uma criatura humana? (LEVI, 1989, p. 14).

A indiferença diante das atrocidades simbólicas e físicas não é novidade na história das barbáries da humanidade. No livro: Genealogia da Moral, Nietzsche (1998) já observara que quanto mais fraca a memória de uma coletividade humana, mais violentas seriam as práticas ritualísticas, na tentativa de que pudesse ser engendrada a internalização e, principalmente, a permanência de determinadas regras de conduta na consciência. É nesse sentido que o filósofo alemão asseverou que a memória vem da dor. $\mathrm{O}$ desenvolvimento da técnica mnemônica dependeria da lembrança da dor sentida com o escopo de que determinados comportamentos deixassem de existir e de que outros fossem, concomitantemente, valorizados. Mas no caso dos prisioneiros de Auschwitz, a intensificação da dor necessitaria ser promovida por meio das mais variadas formas, embora a opacidade de seus olhares, em determinadas situações, já desafiasse cada vez mais a necessidade do aumento da violência e, portanto, da possibilidade de memorização daquilo que seria permitido ou não fazer. Mas a perguntatítulo do livro de Primo Levi: “É isto um homem?” também pode ser aplicada no caso daqueles que lutaram, desesperada e solitariamente, pela própria sobrevivência, nem que para isso tivessem que se embrutecer cada vez mais durante o cotidiano do campo de concentração. Diante da

possível as vítimas para Auschwitz, sem que houvesse a preocupação com o que aconteceria com elas no campo de concentração (ADORNO, 1971, p. 100). 
impossibilidade de expressar o ódio diante dos opressores, o oprimido que tivesse condições de fazê-lo se voltaria contra os próprios oprimidos, sendo inevitável a lembrança do que Paulo Freire (1978) intitulou, na sua Pedagogia do oprimido, como hospedagem do opressor, este sim um dos principais obstáculos para a superação da relação de opressão. O oprimido que hospeda o opressor em si não luta para que a relação oprimido-opressor deixe de existir, mas sim para que possa assumir a condição de opressor. Primo Levi se recorda do caso do prisioneiro Henri, um jovem francês que manipulava as emoções com uma precisão cirúrgica:

Henri descobriu que a piedade, sendo um sentimento primário e irrefletido, viceja muito bem, desde que habilmente transmitida, nas almas primitivas dos brutos que nos comandam, os quais não têm o menor escrúpulo de nos derrubar a socos sem razão e de nos pisotear. Ele percebeu o alcance prático de sua descoberta, na qual inseriu sua indústria pessoal (LEVI, 1989, p. 89).

Henri percebeu que se dissimulasse piedade e consternação diante das tragédias pessoais não só dos seus semelhantes, como também, e principalmente, dos alemães preocupados com a integridade física de parentes que estavam combatendo no front da guerra, ele poderia obter certas benesses, tais como trabalhar em serviços não tão brutalmente desgastantes: ser, por exemplo, transferido para trabalhar na cozinha ao invés de fazer trincheiras durante o inverno. Uma atitude tal como essa de Henri de deliberadamente instrumentalizar as próprias reações afetivas não pode deixar de ser considerada como resultado do processo de desumanização amparado pela racionalidade instrumental que foi utilizada para justificar o extermínio dos considerados "diferentes" por meio de racionalizações técnico-científicas. Não por acaso, no prefácio do livro: "É isto um homem?", Primo Levi argumenta que o campo de concentração é “o produto de uma concepção de mundo levada às suas últimas conseqüências por meio de uma lógica rigorosa" (LEVI, 1989, p. 9).

Mas é justamente a aplicação de tal lógica que desvela o rompimento da promessa da ciência de que seus produtos deveriam ser concebidos para poder amainar o cansaço físico e mental do ser humano, tal como pode ser 
observado no desejo do Galileu brechtiano de que as bombas d'água poderiam trazer muito mais benefícios do que a "ridícula trabalheira sobre-humana" daqueles que se esfalfavam nas plantações, ao mesmo tempo em que sonhavam ter uma vida melhor no pós-morte ao lado de Deus que saberia reconhecer os sacrifícios feitos por seus sequazes (BRECHT, 1977, p. 132-135).

Os engenheiros nazistas, que calcularam quantas "peças" poderiam ser transportadas nos vagões dos trens apinhados de pessoas, são produto do espírito de um tempo, de uma cultura, na qual o esquecimento do que aconteceria com tais pessoas em Auschwitz compactua com um tipo de frialdade que não pode ser exclusivamente atribuída às idiossincrasias da vida um indivíduo. Na verdade, aquilo que Adorno denominou como consciência coisificada se trata, primeiramente, de um fenômeno histórico originado numa sociedade, tal como a alemã, cuja recuperação econômica se deu às expensas da intensificação da indústria bélica capitaneada pelo Estado totalitário. O nazismo deve ser prioritariamente compreendido como acontecimento objetivo, pois se sua tentativa de explicação fosse reduzida aos delírios de um ditador incrivelmente persuasivo, no caso Hitler, se fortaleceria a ideologia do personalismo, ou seja, a de que se Hitler não tivesse existido, também não haveria o próprio nazismo. Evidentemente, a figura do Führer teve grande importância para a disseminação e aceitação coletiva da proposta autoritária nacional-socialista, tal como pode ser observado na argumentação de que esse líder desempenhou papel extremamente relevante no processo de projeção de ideal de ego de seus seguidores nazistas que o idolatravam e, concomitantemente, se identificavam como iguais, formando uma espécie de liame libidinal coletivo autoritário. Porém, o próprio processo projetivo necessita ser investigado de acordo com as mediações históricas que o engendraram. Seguindo essa linha de raciocínio, Adorno e Horkheimer elaboraram relevantes considerações sobre o mecanismo projetivo como uma espécie de função já automatizada no ser humano:

Aprendendo a distinguir, compelido por motivos econômicos, entre sentimentos próprios e alheios, surge a distinção do exterior e do interior, a possibilidade de distanciamento e identificação, a consciência de si e a consciência moral (...) Para refletir uma coisa como 
ela é o sujeito deve devolver-lhe mais do que dela recebe. O sujeito recria o mundo fora dele a partir dos vestígios que o mundo deixa em seus sentidos: a unidade da coisa em suas múltiplas propriedades e estados; e constitui desse modo retroativamente o ego, aprendendo a conferir uma unidade sintética, não apenas às impressões externas, mas também às impressões internas que se separam pouco a pouco daquelas (ADORNO; HORKHEIMER, 1986, p. 175-176).

Quando o indivíduo reflete, ele tende a devolver ao objeto mais daquilo que fora apreendido pelos sentidos, o que possibilita não só a reconfiguração do próprio objeto, por meio dos novos significados que lhe são atribuídos, como também a formação de novas identidades que compõem a unidade do sujeito. Não por acaso, Adorno e Horkheimer destacaram a importância do mecanismo projetivo para a percepção do eu e do mundo, sendo que tal jogo estabelecido entre sujeito e objeto torna-se vital para o surgimento e consolidação tanto da consciência de si quanto da consciência moral, ou melhor, da consciência de si cujos sustentáculos se arvoram nas reflexões sobre os elementos da moral e da ética. Já na psique do seguidor fascista, impera aquilo que os pensadores frankfurtianos chamaram de falsa projeção, a saber:

O patológico no anti-semitismo não é o comportamento projetivo enquanto tal, mas a ausência de reflexão que o caracteriza. Não conseguindo mais devolver ao objeto o que dele recebeu, o sujeito não se torna mais rico, porém mais pobre. Ele perde a reflexão nas duas direções: como não reflete mais o objeto, ele não reflete mais sobre si e perde, assim, a capacidade de diferenciar. Ao invés de ouvir a voz da consciência moral, ele ouve vozes; ao invés de entrar e si mesmo, para fazer o exame de sua própria cobiça de poder, ele atribui a outros os "Protocolos dos Sábios de Sião". Ele incha e se atrofia ao mesmo tempo (ADORNO; HORKHEIMER,1986, p. 176-177).

A falsa projeção pode ser identificada como elemento central da psique nazista, justamente porque a falência dojogo anteriormente destacado entre sujeito e objeto - quando ambas as identidades se pluralizavam por meio da intervenção do sujeito que devolvia mais do que havia recebido do 
objeto - alimenta tanto seu narcisismo quanto sua onipotência paranóica. A falência do jogo de reconfiguração da relação sujeito e objeto, imposta pela supremacia da falsa projeção, pode ser também caracterizada como uma falência do processo educacional/formativo, pois a impossibilidade de formação de novas identidades encontra esteio na dessensibilização e, portanto, na desumanização.

Assim, aqueles que ousam "seduzir" o seguidor nazista com maus exemplos devem ser exterminados, pois ele jamais poderá assumir o quão inveja o intelectual pela possibilidade de questionamento em relação a uma ordem determinada, ou mesmo do homossexual que tem a petulância de não obedecer as ordens do discurso oficial que lhe impõe um tipo de exercício da sexualidade. Para os nazistas, os responsáveis por tais sortilégios deveriam ser exterminados, uma vez que, de acordo com a lógica delirante paranóica, eles seriam os verdadeiros culpados por quaisquer confusões ou hesitações que pudessem vir a ocorrer. Caso optassem entre reflexos ou reflexões, os sequazes nazistas não vacilariam em escolher a primeira opção. ${ }^{2}$ Mas a hegemonia do pensamento estereotipado adquire outras tonalidades nas sociedades ditas democráticas. Em tais sociedades, tal como a dos Estados Unidos da década de quarenta do século passado,

A experiência é substituída pelo clichê e a imaginação ativa na experiência pela recepção ávida. Sob pena de uma rápida ruína, os membros de cada camada social devem engolir suas doses de orientações (...) No mundo da produção em série, a estereotipia - que é o seu esquema, substitui o trabalho categorial. O juízo não se apóia mais numa síntese efetivamente realizada, mas numa cega subsunção (...) Se, no interior da própria lógica, o conceito cai sobre o particular como algo de puramente exterior, com muito mais razão, na sociedade, tudo que representa a diferença tem que tremer. As etiquetas são coladas: ou se é amigo, ou inimigo (ADORNO; HORKHEIMER, 1986, p. 187-188).

\footnotetext{
${ }^{2}$ Mario Quintana, no seu Caderno H, expôs tal impasse da seguinte forma: "Os velhos espelhos adoram ficar no escuro das salas desertas. Porque todo o seu problema, que até parece humano, é apenas o seguinte: - reflexos? Ou reflexões?" (QUINTANA, 1983, p. 15).
} 
Esse processo de substituição da imaginação ativa pelo clichê foi denominado por Adorno e Horkheimer como mentalidade do ticket. Os conflitos de opinião que poderiam estimular o indivíduo a rever sua posição aparentemente irredutível deveriam ser prontamente evitados. Ou seja, a defesa das etiquetas teria a pretensão de promover ao menos duas sensações imanentemente prazerosas: a de conforto, uma vez que mundo não seria tão complicado quanto aparentava ser, pois bastaria saber distinguir os que são amigos dos que são inimigos; e a de estar integrado e se aproximar de "iguais" que pensariam de forma semelhante, mesmo que isso fosse feito às custas do ódio em relação àquele que não seria partidário das mesmas ideias e nem portaria os mesmos signos de identificação. Não por acaso, Adorno e Horkheimer, ao caracterizarem a chamada mentalidade do ticket, observaram que esse processo de danificação da autoreflexão do espírito ocorre, no contexto do capitalismo tardio, mediante a universalização da semicultura (Halbbildung) ${ }^{3}$ convertida como espírito objetivo (ADORNO; HORKHEIMER, 1986, p. 184).

A conquista do espírito pela lógica universalizada da mercadoria cobra seus dividendos também na esfera da produção de bens simbólicos, de tal modo que o indivíduo semiformado não se sente estimulado a refletir criticamente sobre o que aprende, pois dificilmente consegue apreender algum conhecimento por um tempo que o capacite a elaborá-lo a ponto de poder ressignificar sua própria vida. A máxima de que não há tempo a perder é orgulhosamente assumida pelo indivíduo semiformado que, diante da velocidade de reposição das informações, se identifica como alguém que precisa saber de tudo um pouco, mesmo às expensas da superficialidade em que tais informações são absorvidas. É por isso que a semiformação pode ser caracterizada como "fraqueza em relação ao tempo, à memória, única mediação que realiza na consciência aquela síntese da experiência que caracterizou a formação cultural em outros tempos" (ADORNO, 1996, p. 406).

O arrefecimento da capacidade mnemônica ocorre concomitantemente ao fortalecimento da mentalidade do ticket. Adistinção,

\footnotetext{
${ }^{3} \mathrm{O}$ termo alemão Halbbildung pode, dependendo do contexto, ser traduzido como semicultura ou semiformação, caso a ênfase recaia, respectivamente, ao processo de danificação objetiva e/ou subjetiva da produção cultural.
} 
muitas vezes autoritária, entre os que participam de um determinado grupo e aqueles que devem ser colocados à margem, desconsidera as mediações históricas que foram responsáveis pelo acirramento do narcisismo das pequenas diferenças entre os que se esforçam para, desesperadamente solapar o fato de que são mais próximos do que pensam daqueles que, aparentemente, são tão diferentes. A mentalidade do ticket desvela as engrenagens sociais da esteira da semiformação, na medida em que os indivíduos são etiquetados com determinados rótulos sadicamente degustados nas ocasiões em que os marginalizados, isto é, os que não pertencem ao círculo dos eleitos, são agredidos física e simbolicamente. Portanto, levada ao extremo, tal lógica de padronização revitaliza o pensamento fascista de que aqueles que não pertencem à coletividade, autoritária e libidinalmente ligada, devem ser exterminados, tal como ocorre atualmente nas chamadas torcidas organizadas de futebol.

Mas este fenômeno de diferenciação autoritariamente narcísica não pode ser imputado exclusivamente às agressões físicas e simbólicas cometidas principalmente pelos membros das chamadas torcidas organizadas de futebol. São cada vez mais notórios os casos das agressões físicas e simbólicas presentes entre os alunos de uma escola que portam determinados logotipos em suas vestimentas e ridicularizam ou mesmo batem nos alunos que não possuem tal ícone em suas roupas. A afirmação autoritária da identidade, seja ela particular ou coletiva, também encontra espaço para vicejar em ambientes aparentemente democráticos. De tempos em tempos, surgem determinados conceitos que, como num passe de mágica, adquirem o poder de se tornarem autoexplicativos, tal como o denominado bullying escolar, cuja simples menção parece proporcionar não só a identificação da violência praticada nos ambientes escolares como também o seu controle. A exemplo do que já ocorrera com o conceito de estresse, também no caso do bullying os "sintomas" são identificados como as causas dos comportamentos agressivos. Na verdade, tais práticas de violência precisam ser investigadas e compreendidas no contexto em que a hegemonia da indústria cultural reforça progressivamente tanto o enfraquecimento do processo educativo/formativo, no qual a autoconsciência se forma por meio da reflexão sobre a dolorosa sublimação dos desejos que se dá no embate cotidiano da afirmação dos direitos e 
deveres, quanto a tentativa açodada de recuperar o controle da identidade por meio do esfacelamento do outro, ou seja, daquele que não pertence à turma, para fazer uso de uma gíria atual bastante utilizada e bem elucidativa de tal processo.

Numa sociedade de produção em massa de mercadorias, as quais já nas primeiras décadas do século vinte travavam uma luta titânica entre si para que pudessem capturar a atenção dos prováveis consumidores, o pavor de se sentir pulverizado no meio da multidão de mônadas ${ }^{4}$, cujas identidades fragmentadas clamavam para serem reconhecidas, seria compensado por meio do vínculo estabelecido muitas vezes de forma autoritária.

O sacrifício da própria individualidade não seria identificado como tal por aquele que se privaria de questionar sua entrega aos mandos e desmandos de uma determinada coletividade, pois a anulação da individualidade seria condição determinante para a possibilidade de ser respeitado pelos que procederiam da mesma forma. Nesse caso, o indivíduo se aferraria, kantianamente falando, à sua condição de menoridade justamente por se submeter à tutelagem daqueles que fazem parte de um grupo. A questão é que tal menoridade seria dissimulada diante da onipotência narcísica de se sentir maior frente àqueles que não compactuam com tal entrega.

\section{A atualidade da Indústria Cultural, a Semiformação e o prazer da indiferença à barbárie}

Como foi anteriormente observado, o preconceito delirante nos grupos de torcedores que, em muitas ocasiões, massacram aqueles que não portam seus logotipos de reconhecimento - no caso o escudo de uma determinada agremiação de futebol - não pode ser unicamente associado

4 Tal pavor foi magistralmente descrito no conto de Edgar Alan Poe intitulado: "O homem da multidão". Poe descreve as agruras da personagem que teme desesperadamente permanecer sozinho consigo mesmo, de tal maneira que não consegue mais viver se não estiver rodeado de pessoas, ou seja, imerso numa multidão formada por indivíduos isolados entre si e praticamente incapazes de se relacionar profundamente (POE, 1977, p. 107). 
a tal situação, pois também se faz presente tanto na violência física dos Skinheads que assassinam simpatizantes de heavy metal, quanto na violência simbólica dos adolescentes que humilham outros que não vestem roupas com a mesma marca nos pátios dos ambientes escolares. Não por acaso, se faz cada vez mais oportuna a observação de Adorno e Horkheimer, presente na Dialética do Esclarecimento, de que a publicidade já na década de quarenta do século passado se tornara o elixir da vida da indústria cultural (ADORNO; HORKHEIMER, 1986, p. 151). A luta pela posse do logotipo e dos atributos a ele associados já demonstrava indícios de quão decisiva tal posse se tornaria, décadas mais tarde, para a construção das "identidades" das pessoas, dos produtos, ou de ambos.

Mas há grandes diferenças entre a força dessa observação, feita no apogeu do capitalismo monopolista, e a forma como indústria cultural e publicidade se amalgamam no atual capitalismo transnacional. Logotipos de empresas transnacionais, tais como Nike, Adidas ou Coca-Cola devem ser propagandeados não apenas como se fossem meros representantes de produtos concretos, mas devem sim ser vinculados a determinados estilos de vida. Suas imagens necessitam ser imediatamente ligadas à "verdadeira e original" forma de se praticar esporte, tal como ocorre nas contendas mundiais entre a Nike e a Adidas, cujos logos digladiam-se com o objetivo de ser reconhecido como a quinta-essência do que significa praticar esporte. Naomi Klein faz uma série de pertinentes considerações sobre as diferenças entre os sentidos da publicidade na aurora do capitalismo monopolista e nos dias atuais:

Diante de um leque de produtos recentemente inventados - rádio, fonógrafo, carro, lâmpada elétrica e assim por diante, os publicitários tinham tarefas mais prementes do que criar uma identidade de marca para qualquer corporação; primeiro tinham que mudar o modo como as pessoas viviam (...) Muitos desses novos produtos traziam marcas - e algumas delas estão por aí hoje - mas isso era quase incidental. Esses produtos eram em si mesmo uma novidade; e isso praticamente bastava como publicidade (KLEIN, 2003, p. 29). 
Porém, essa postura publicitária quase que idílica, se comparada com a dos dias de hoje, precisou ser modificada na medida em que a produção em massa de fogões, carros e lâmpadas, por exemplo, se afirmava como uma espécie de caminho sem volta, fato esse que desafiou os publicitários a encontrar maneiras que incitassem o consumidor a preferir a marca de um fogão em detrimento de outra (HELLMANN, 2003, p. 85). É por esse motivo que a "marca competitiva tornou-se uma necessidade da era da máquina", pois, "a diferença baseada na imagem tinha que ser fabricada junto com o produto" (KLEIN, 2003, p. 30). A busca por essa imagem diferenciada se fundamentava na intenção de se fazer com o que os produtos se tornassem cada vez mais "humanos", ou seja, que recordassem às consciências reificadas dos consumidores sua condição de objetos produzidos por estes mesmos consumidores e que, sendo assim, portariam suas respectivas idiossincrasias humanas. Evidentemente isso foi feito não com o escopo de se reapropriar criticamente da história das relações humanas responsáveis pela tessitura da forma e do conteúdo das mercadorias, mas sim para reafirmar o poderio da própria reificação.

Não apenas a imagem do produto deveria se metamorfosear no sentimento humano desejado de ser incorporado, mas também a própria marca da empresa agregaria tal significado, ou seja, a imagem de uma velha senhora negra que estampava as caixas de aveia Quaker estimularia a presença de uma sensação de familiaridade aliada não apenas à aveia, mas principalmente em relação à marca Quaker. (KLEIN, 2003, p. 30). De lá para cá, nota-se a exacerbação avassaladora do capital investido nas imagens publicitárias dos produtos, de tal modo que, de acordo com os dados do relatório de desenvolvimento humano das nações unidas de 1998, o crescimento nos gastos globais com publicidade superava, na época, "o crescimento da economia mundial em um terço" (KLEIN, 2003, p. 32). O modo como se produz e se reproduz capital no capitalismo transnacional impinge a hegemonia das projeções imagéticas não só das marcas das mercadorias, como também dos derivativos financeiros, cujas especulações "sustentarão" as bases do mercado cada vez mais futuro. De acordo com Laymert Gacia dos Santos, 
O sistema financeiro internacional mudou-se para o ciberespaço, e talvez seja por isso que o mundo esteja sofrendo de grande instabilidade financeira (...) Antes de mais nada, cabe salientar que a transferência se manifesta mais visivelmente como desinteresse pela produção material e desistência do investimento produtivo: em cada 70 dólares que trocam de mãos nos mercados cambais globais, só um paga por comércio de bens ou serviços, muitas das transações são especulativas: é que os investidores tentam tirar vantagem de pequenas diferenças nas taxas de câmbio ou de pequenos diferenciais nas taxas de juros, medidos em frações de percentagens (SANTOS, 2003, p. 115).

De fato, estamos diante da confirmação do maior prognóstico econômico-político de Marx e Engels exposto no Manifesto comunista, a saber: tudo que é sólido desmancha no ar, ou seja, com o desenvolvimento do modo de produção capitalista: "Todas as relações firmes, sólidas, com suas séries de preconceitos e opiniões antigas e veneráveis foram varridas, todas as novas tornaram-se antiquadas antes que pudessem ossificar" (MARX; ENGELS, 1998, p. 14). Se ambos aparentemente se equivocaram, pelo menos até o presente momento, quando vaticinaram a destruição do capitalismo, por meio do acirramento das contradições internas entre as relações de produção e as forças produtivas, não se pode desconsiderar a magnitude desta assertiva, ou seja, do quão volatilizados se tornam as mercadorias e as identidades de seus produtores, principalmente na sociedade cujo sistema financeiro se transfere, hegemonicamente, para o ciberespaço.

Portanto, o entendimento das características de tal volatilidade precisa ser feito considerando-se o atual estágio de desenvolvimento do modo de produção capitalista, pois a consolidação de sua transnacionalidade depende da aliança da informática com as telecomunicações, de tal modo que se torna possível, eletronicamente e em tempo real, "rastrear riscos e recursos que possam gerar valor" (MARX; ENGELS, p. 118) no contexto de fusões, cada vez mais presentes, entre as grandes corporações que projetam derivativos imagéticos futuros relacionados aos ativos atuais de seus respectivos produtos. A supremacia da produção dos derivativos imagéticos na dimensão econômica, ou seja, das imagens financeiras 
acordadas entre compradores e vendedores que servirão de "base" para a realização de pagamentos futuros, associa-se à necessidade imperiosa de que o mercado dos chamados produtos culturais também se fie sob a égide das megacorporações, cujas imagens logotípicas devem ser estampadas das mais variadas formas e estar no mais diferentes lugares. A pretensão de transformar o logotipo de uma determinada marca num estilo, numa realidade de vida, implica na importância da não separação dos espaços e tempos nos quais se poderiam consumir os produtos representados por tais logos. Sendo assim,

(...) a meta não é apenas ter atores mirins bebendo Coca-Cola em um comercial de TV, mas que os estudantes debatam conceitos para a próxima campanha publicitária da Coca-Cola nas aulas de inglês (...) A marca Disney transcende sua rede de esportes ESPN, um canal para rapazes que gostam de se sentar em bares gritando diante da TV, e lança uma linha de bares ESPN com telões de TVs e tudo (KLEIN, 2003, p. 53).

A "ambição" do produto de ter sua marca transcendentalmente presente em todos os lugares e situações, até atingir o ponto de ser associada a um estilo de vida, é muito bem ilustrada no caso dos debates de tais alunos nas aulas de inglês, ou em qualquer outra situação corriqueira, sobre os rumos das próximas campanhas publicitárias da Coca-Cola. Esse "estar aí" onipresente das imagens de tais produtos revela, na verdade, um paradoxo de extrema atualidade e que nos ajuda a compreender as características da indústria cultural hodierna, qual seja, o enfraquecimento da capacidade humana de construção de representações em meio à farta proliferação de imagens. A contínua difusão de imagens, ao invés de servir de lastro para o pensamento se sentir estimulado a relacionar uma gama de significados aos objetos representados, parece intensificar a associação de um determinado significado ao produto propagandeado. O slogan da Nike: Just do it sintetiza muito bem o desejo do gozo imediato, ao mesmo tempo em que se desconsidera quaisquer reflexões contrárias a esse tipo de comportamento imediatista. É como se a palavra de ordem: "Apenas faça isso!" desqualificasse por si só 
alternativas de identidade que não fossem atreladas ao estilo de vida, ao life style de se praticar esporte do jeito Nike de ser.

A danificação da capacidade de se construir representações, tal como foi observado anteriormente, é uma condição decisiva para a revitalização da chamada mentalidade do ticket e, portanto, da lógica binária que identifica o outro como amigo ou inimigo, como digno de ser respeitado ou de ser humilhado, ou mesmo morto. O processo de elaboração das imagens, cuja força se baliza na necessidade de que o indivíduo devolva mais do que recebeu do objeto, se estilhaça do mesmo modo como a própria identidade do indivíduo se fragmenta, com intensidade cada vez maior, por conta da atual ação dos chamados aparelhos tecnológicos de distração. Günther Anders elucidou esse processo com o exemplo do "homem tomando banho de sol",

que bronzeia suas costas, enquanto que seus olhos deslizam por uma revista ilustrada, seus ouvidos participam de jogo esportivo, seus dentes mascam uma goma (...) Se fosse perguntado a este homem tomando banho de sol no que consistiria sua atividade "real", é claro que ele não poderia responder, pois a pergunta por algo de "real" já se baseia em uma falsa pressuposição; a saber, que ele seria o sujeito das atividades e do deter-se em algo. Se aqui ainda se pode falar de "sujeito" ou "sujeitos", os termos têm que se referir aos seus órgãos: aos olhos que se detêm sobre as fotos; aos ouvidos que se detêm sobre os jogos esportivos; aos dentes que se detêm sobre a goma de mascar (...) Seu trabalho acostumou-o tão definitivamente a ser ocupado, ou seja, a ser dependente, que, quando o trabalho acaba, não consegue estar à altura da tarefa de ocupar de si próprio". E, assim, (...) “decompõe-se em funções separadas, já que ele mesmo não atua como elemento organizador (ANDERS, 2002, p. 138-139).

O chamado "homem no banho de sol" parece assumir a pecha de ser uma metáfora que anuncia o crepúsculo da própria, ou seja, a proliferação de significados que as imagens metafóricas portam consigo se arrefece na mesma proporção em que disseminam as imagens das marcas que aludem a um determinado significado. Tais logotipos imagéticos almejam ter o poder de não só ditar o ritmo e o estilo da vida, como também de ressignificar a identidade 
daquele que não suporta mais ter que refletir sobre seu próprio estado de fragmentação. A ressignificação da identidade do particular nesses termos também aduz a maneira como tais fragmentos de identidade se "relacionam" em massas aparentemente amorfas. De acordo com Vílem Flusser,

A dispersão da sociedade, a dissipação de grupos em grãos, vai transformando a humanidade em massa aparentemente amorfa. A exfamília em torno da TV não mais se estrutura por laços intra-humanos, ela se desintegrou. As pessoas em cinema, geometricamente ordenadas pelas poltronas, não se estruturam mais por laços intra-humanos: não são grupo, mas massa disforme. A criançada que brinca com o computador dá as costas uns aos outros, e quando adultos não mais terá nem "consciência social", nem de família, nem de classe, nem de povo: desintegrou-se (FLUSSER, 2008, p. 67).

O atual "homem da multidão" tem sua identidade fragmentada em múltiplas funções diante do contato com os atuais aparatos tecnológicos de distração, tais como a televisão e o computador, os quais exigem a atenção focada nas sequências intermináveis de imagens que parecem não só falar por si, como também por aqueles que as assistem. Nossa atenção é concentrada em informações imagéticas para logo em seguida ser pulverizada, uma vez que tal informação é imediatamente substituída por outra num ritmo alucinante. As indiscutíveis benesses, que são produzidas quando o indivíduo acessa instantaneamente as mais variadas informações, não pode obnubilar o fato de que a atual indústria cultural desestimula o engendramento de relações entre tais elementos informativos. E que isso obstaculiza a realização do salto qualitativo da informação que se conservaria transformada em formação (Bildung), na medida em que houvesse o tempo necessário para reflexão dos conteúdos assimilados. Diante desse quadro, pode-se identificar o sentido do nonsense, da ausência de sentido de se contactar com tantos aparelhos de televisão em lugares e situações inimagináveis até pouco bem pouco tempo atrás, tais como trens de metrô, consultórios médicos, lojas de todos os tipos, restaurantes e, até mesmo, elevadores. O fato é que as pessoas precisam do contato com potentes estímulos audiovisuais, pois se viciam neles, de tal modo 
que o conceito de vício não pode mais ser limitado à dimensão psíquica ou mesmo fisiológica. A forma como se produz e reproduz a indústria cultural contemporânea impinge mudanças no conceito de vício que passa a adquirir o status de categoria psicossocial (TÜRCKE, 2002). Os indivíduos não mais se contentam com, digamos, o prazer de assistir a um filme sobre sequestro, pois precisam "presenciar" o sequestro em tempo real por meio do contato com as imagens de transmitidas pela internet ou pela televisão.

A compulsão generalizada pelo consumo de estímulos audiovisuais, cada vez mais agressivos, significa também o declínio da capacidade de representação do indivíduo que, gradativamente, não mais se interessa pelo acontecimento representado, mas sim exige a sua manifestação aqui e agora, de preferência ao vivo e à cores. Acirra-se, desse modo, a interdependência de dois elementos aparentemente antagônicos, ou seja, a sensibilização e a dessensibilização, pois o estado de torpor do indivíduo, que não mais se impressiona com a tragédia repetida ad nauseum pelos meios de comunicação de massa, precisa ser abalado diante de um acontecimento mais horroroso. Ou seja, após tal acontecimento, conquistar a atenção do indivíduo, que se sensibiliza diante do infortúnio alheio, engendra-se novamente a frieza e o esquecimento de tal situação, uma vez que algo mais terrível passa a ser divulgado como uma "novidade" ainda mais sedutora. Sadomasoquismo e frieza são, de fato, dois dos principais componentes da dimensão subjetiva concernente à mercantilização dos produtos "simbólicos". A ironia da aspas se justifica, pois, como foi dito anteriormente, esses atuais produtos simbólicos suscitam cada vez menos a formação de representações, ao mesmo tempo em que suas imagens se aferram a um determinado significado.

Seguindo essa linha de raciocínio, a presente forma de mercantilização desses produtos consagra a hegemonia da chamada falsa projeção em detrimento da capacidade projetiva que possibilitava delimitar as fronteiras entre a identidade do indivíduo e a do outro, numa espécie de revitalização do conceito de semiformação, elaborado por Theodor W. Adorno. Ao refletir sobre as diferenças entre seus desejos e as vontades alheias, o indivíduo é capaz de não só discernir sobre os limites de suas ações quanto também realizar, quando necessário, sua autocrítica em relação a uma determinada situação. 
Mas, no contexto da atual semiformação, cada vez mais aumenta a incapacidade do indivíduo de fixar sua atenção numa determinada informação, a ponto de poder elaborá-la como conhecimento. Milhares de informações, vinculadas pelos sites da internet, disputam entre si a possibilidade de capturar a nossa atenção - concentrada numa determinada informação que se confunde, não de forma fortuita, com um estímulo audiovisual - a qual se pulveriza assim que nos interessamos pelo apelo chamativo de outros links virtuais. A verdade de que não se pode ignorar as facilidades, sobretudo as que envolvem a coleta de dados, que um simples clicar de mause oferta, quando investigamos e comparamos a forma como um conceito foi elaborado por um pensador no início e no final de sua vida, não pode servir como justificativa da ausência frequente dessa preocupação histórica, diante da aparente inevitabilidade do processo de pulverização de nossa capacidade de concentração. Na sociedade atual, o conceito de vício não pode mais se restringir à dimensão particular, pois amealha uma conotação psicossocial, principalmente quando é aplicado para compreender os desdobramentos consequentes de nossa interação com o consumo dos estímulos audiovisuais.

Em tempos nos quais o computador não mais se limita a proporcionar o contato afetivo com outras pessoas, mas sim adquire prerrogativa de ser um aparelho utilizado para relações de trabalho, diversão, televisão, entre tantas outras funções, observa-se a presença de um comportamento de vício, tal como se, por exemplo, a caixa de e-mails nos "chamasse" a todo instante para verificarmos a existência de novas mensagens. Tal como foi observado anteriormente, o imperativo do consumo dos estímulos audiovisuais é tamanho que não é mera coincidência o fato de nos depararmos com telas de televisão em praticamente todas as situações de convívio, sejam elas particulares ou coletivas. Diante desse quadro, é revestida de grande sarcasmo a propaganda da rede de televisão a cabo que promete, enfim, promover a tão sonhada reunião familiar, ou seja, todos reunidos em frente ao aparelho de televisão, cujo silêncio dos membros familiares se faz ouvir diante dos gritos dos apresentadores que tentam desesperadamente comercializar seus produtos.

Ao discutir o provável desaparecimento da infância, ao menos a noção de infância consagrada durante a modernidade, Postman destacou 
a ausência de segredos como consequência produzida pela fratura da relação espaço-temporal que existia antes da aceleração e do consumo alucinante de informações, os quais são característicos da sociedade dos meios de comunicação de massa, sobretudo da era da televisão. De acordo com o argumento de Postman, o gradativo processo de assimilação dos conhecimentos, que ocorrera durante o processo de alfabetização após a disseminação do livro, demarcava não só as características da identidade do adulto, como também as da criança que necessitava do tempo necessário para poder elaborar determinado conhecimento e adquirir, com o tempo, as habilidades necessárias para ter o domínio de certos assuntos.

A capacidade de elaborar representações e, portanto, de estimular a imaginação, era incrivelmente promovida, sobretudo por meio do contato de indícios de informações - pensemos no caso da esfera sexual, por exemplo - que a criança tinha, ao mesmo tempo em que era cônscia do fato de que só teria acesso à posse e ao controle de tais informações durante o seu processo de se tornar adulto. Mas, e numa sociedade onde praticamente não há mais segredos?

Para Postman, "na Idade Média não havia crianças porque não havia para os adultos meios de contar com informação exclusiva. $\mathrm{Na}$ era de Gutenberg surgiu esse meio. Na era da televisão ele se dissolveu" (POSTMAN, 1999, p. 99). Assim, a tendência majoritária da televisão é a de solapar a capacidade de abstração e de tornar tudo concreto por meio da difusão de suas imagens autoexplicativas, de tal modo que também são abaladas as conquistas de uma cultura plenamente letrada que alicerçam a maturidade do indivíduo, tais como "a capacidade de autocontrole, uma tolerância para com o adiamento da satisfação, uma refinada capacidade de pensar conceitualmente e em sequência, uma preocupação com a continuidade histórica e com o futuro, uma alta valorização da razão e da ordem hierárquica" (POSTAMN, 1999, p. 113).

Crianças se "adultificam" precocemente - vide o fenômeno da precocidade cada vez maior com que as meninas menstruam -, assim como os adultos se tornam cada vez mais infantilizados. Esses hibridismos não podem ser exclusivamente identificados como consequências diretas da influência dos meios de comunicação de massas, tal como a televisão, mas sim devem ser compreendidos como fenômenos de uma sociedade 
cuja lógica do fetiche das mercadorias se universaliza, aí sim, por meio da tecnologia midiática. Paradoxalmente, a atual universalização do trabalho abstrato, assim como os abalos das costumeiras linhas divisórias entre trabalho e tempo livre, parece enfraquecer a capacidade de abstração que servia de liga para a reflexão e reformulação da dimensão concreta. Numa sociedade capitalista globalizada que virtualiza tanto a esfera objetiva quanto a subjetiva, a ânsia pelo concreto generaliza a atitude fundamentalista daquele que se aferra libidinalmente a determinado logotipo, e às pessoas que o portam, como se fosse o último refúgio da vida, nem que tenha que, para isso, literalmente eliminar os outros que não fazem parte do grupo eleito.

Nesse contexto social, o enfraquecimento da capacidade de representação debilita também a possibilidade de que sentimentos morais, tal como a vergonha, se tornem elementos constituintes da estrutura de personalidade desses mesmos indivíduos. A vergonha como sentimento moral se alimenta do permanecer, na consciência, daquilo que incomodou o outro, fazendo com que o indivíduo faltoso reflita sobre as consequências de seu comportamento e evite praticá-las numa situação futura semelhante à atual. Deste modo, na mesma proporção em que a capacidade de representação se enfraquece, a frialdade se dissemina com força cada vez maior. Não que tal sentimento fosse produção exclusiva do modo de produção capitalista. Mas, por outro lado, é nesse atual contexto histórico que a frialdade cada vez mais assume a característica de forma de percepção universal (GRUSCHKA, 1994, p. 35-43). Quando a frieza assume a condição de caráter normativo de tal magnitude, então se torna extremamente atual a adevertência deAdorno de que a educação deve refletir, de forma contundente, a respeito da reincidência de práticas totalitárias simpáticas ao que aconteceu em Auschwitz. O próprio frankfurtiano destacou na sua palestra Educação após Auschwitz que, provavelmente, o fracasso da crítica cristã à dessensibilização e ao estado de torpor do indivíduo, diante do sofrimento alheio, ocorrera por conta do fato de que cristianismo não atingira o cerne da questão, ou seja, a indiferença frente ao horror se metamorfoseia no espírito de um tempo no qual as atuais formas mercantilizadas de produção da existência humana determinam o modo como a frialdade se universaliza como forma de se perceber o mundo. 
A força do consciente coisificado se alastra na sociedade cujas relações de produção promovem a internalização do fetiche da mercadoria até mesmo na dimensão inconsciente. A dificuldade de se distinguir os limites entre ações patológicas e não patológicas, mediadas pelo uso dos aparatos tecnológicos, tem relação organicamente visceral com a reprodução da própria frieza. Adorno já destacara tal dilema da seguinte forma:

As pessoas inclinam-se a considerar a técnica como algo em si, como um fim em si mesmo, como uma força com vida própria. Mas com isso se esquecem que ela se trata do braço prolongado do homem. Os meios, e a tecnologia é a essência dos meios para a autopreservação da espécie humana, são fetichizados porque os fins - uma existência digna do ser humano - são encobertos e apartados do consciente humano (ADORNO, 1971, p. 100).

Frases tais como: "Meu carro é minha vida!", tão "saborosamente" degustadas por meio das propagandas de televisão, não podem ser rotuladas como algo exclusivamente restrito às características particulares do indivíduo, mas sim devem ser identificadas como uma terrível ilustração da cultura na qual o uso da técnica deixa de apenas referendar a tecnologia como modus operandi ao transformá-la numa espécie de modus vivendi coisificado. Ou seja, um modus vivendi que reconhece como seus aqueles que projetam sua libido muito mais nas coisas do que nas próprias pessoas. A supremacia desse modo de viver tecnologicamente coisificado não ocorre, majoritariamente, naquele sentido exposto pelo Galileu brechtiano, de que as bombas d'água poriam fim à "ridícula trabalheira sobre humana" ao amainarem tanto o cansaço físico quanto mental. Na verdade, nessa pretensão de Galileu, já se nota tanto a esperança de dias melhores, que poderiam se tornar uma realidade frente à substituição da fé pela ciência, quanto a soberba dessa mesma ciência que, historicamente, se afasta de seu objetivo original de contribuir para uma existência humana digna. Esse afastamento foi bem caracterizado pelas palavras de Horkheimer de que "a relação entre hipótese e fato, não se realiza na cabeça dos cientistas, mas na indústria" (HORKHEIMER, 1991, p. 37).

O processo de coisificação não pode ser observado exclusivamente 
nas práticas científicas desenvolvidas nas indústrias, mas também na esfera educacional. Nesse sentido, Adorno criticou a produção dessa consciência coisificada também em relação à chamada educação para a disciplina por meio da dureza, na qual os educandos de "caráter" seriam aqueles que não manifestariam seus descontentamentos em relação a seus professores, mas sim reprimiriam a raiva de tal modo que, quando se tornassem futuros educadores, poderiam se vingar, em seus alunos, daquela dor que tiverem que reprimir. A repressão do medo e/ou angústia por parte dos alunos, já lembrava Adorno com uma interessante chave de leitura psicanalítica, tenderia a produzir efeitos futuros incrivelmente destrutivos.

Atualmente, os alunos parecem encontrar, no uso dos recursos tecnológicos, principalmente a internet, o "local" para expor a raiva reprimida durante o cotidiano das atividades escolares, haja vista a quantidade avassaladora, e que não para de crescer, de comunidades no Orkut cujos alunos se queixam do comportamento muitas vezes autoritário de seus mestres e das cenas gravadas nos vídeos do Youtube, nos quais os alunos humilham seus professores das mais variadas formas. $\mathrm{Na}$ sociedade de supremacia das marcas e do imperativo de que ser significa ser percebido publicamente (TÜRCKE, 2002), os alunos utilizam os recursos tecnológicos de produção de choques audiovisuais com o objetivo não só de, sadicamente, se vingar da dor masoquistamente reprimida, mas também de se tornar uma propaganda de si mesmo, como se eles próprios se transformassem em tais choques. Eles já não mais precisam esperar tanto tempo para expor a dor reprimida em sala de aula, pois o instantâneo do click da câmera do celular, que registra a imagem do professor ridicularizado pelas costas por seus alunos, representa também a realização instantânea do desejo de humilhar e agredir, desejo esse que não pôde se manifestar explicitamente durante o cotidiano escolar, em virtude do receio de se sofrer algum tipo de retaliação, mas que se publiciza no mundo todo por meio das imagens difundidas no Youtube.

\section{Conclusão}

O atual arrefecimento da capacidade de representação e da reflexão sobre o caráter histórico das imagens, que parecem adquirir vida própria, 
alude tanto à dimensão objetiva, no caso dos chamados derivativos imagéticos que parecem não ter relação com os ativos reais, pelo menos até o momento em que a crise da especulação financeira cobra seus dividendos concretos, quanto na dimensão subjetiva, principalmente quando a marca dos produtos "simbólicos" consegue ser identificada com um estilo de vida que deve ser apropriado para se possa viver e ser reconhecido como "sujeito", como "interventor". Nesse sentido, talvez não fosse exacerbada a assertiva de que o enfraquecimento da memória e, portanto, da capacidade de representação, necessita do estilhaçamento das mediações históricas como pré-condição de sua existência. $\mathrm{O}$ arrefecimento do liame histórico estimula o indivíduo semiformado a desconsiderar possíveis incômodos que seriam engendrados por meio da sensibilização diante da dor alheia.

$\mathrm{Na}$ verdade, toda imagem é representação do real. Guy Debord já nos alertava, na Sociedade do Espetáculo, que “o espetáculo não é um conjunto de imagens, mas uma relação social entre pessoas, mediada por imagens" (DEBORD, 1997, p. 14). Só que nos dias atuais, a imagem se aproxima tão espetacularmente da realidade, por meio do aparato tecnológico da atual indústria cultural, que o abstrato e concreto parecem se fundir. Mas, nessa situação, "o abstrato e o concreto não se colocam, num contexto de referência, nas condições de significado e significante, de essência e aparência, pois eles não significam e representam um ao outro, mas sim se penetram e se tornam irreconhecíveis entre si" (TÜRCKE, 2002, p. 288).

A presente irreconhecibilidade entre o abstrato e o concreto é resultado da produção de um determinado espírito de um tempo, ou seja, de uma cultura cujo processo de danifificação revitaliza as considerações de Adorno sobre os prejuízos concernentes à universalização da semiformação, pois, cada vez mais, o semiformado se torna incapaz de elaborar, na forma de conhecimento, as informações difundidas pelos atuais meios de comunicação de massa. O atual estilhaçamento do eu e de sua capacidade de concentração são simbolizados pela imagem do "homem do banho de sol", de Günther Anders, na medida em que os atuais aparelhos tecnológicos de distração originam uma espécie de esquizofrenia artificialmente produzida. O caso do "homem no banho de sol" é paradigmático desse estado em que o indivíduo não mais se assenhora de si mesmo e, talvez, nem mais 
queira fazê-lo, pois sua indentidade se esfacela na miríade de funções particularizadas. São seus orgãos que, mediados tecnologicamente, parecem ser os responsáveis pela "organização" de identidades pulverizadas como se, dinamizados pelos aparelhos tecnológicos de distração, fossem completamente autosuficientes e independentes entre si.

O homem, idílica, natural e ironicamente apresentado por Anders que se banha no sol, tem pavor de se deparar com quaisquer situações que estimulem a possibilidade de um reecontro consigo mesmo. Tratase de um eu "integrado" por meio de unidades sensoriais multifacetadas que dificilmente se relacionam entre si. A ocupação compulsiva de todos os seus sentidos amaina seu desespero interior de ter que refletir sobre o vazio de sua própria existência. Não por acaso, tal fragmentação pode ser vislumbrada como o avesso do intento pedagógico de Rousseau (1992), principalmente no que concerne à relevância da denominada razão perceptiva caracterizada no seu: Emílio ou da educação, ou seja, o filósofo genebrino exaltou as disposições humanas capazes de incitar uma tal comunicação entre os sentidos que seria determinante para o incremento da riqueza de representações e, portanto de reflexões sobre o equilíbrio entre a vontade e as faculdades responsáveis por sua realização. Dito de outro modo, o aluno gradativamente seria instigado a refletir sobre o necessário equilíbrio entre o desejo e as leis que garantiriam o cumprimento dos contratos sociais firmados pela vontade coletiva.

O estado de aparente naturalidade do homem no banho de sol é a antítese pedagógica daquilo que Rousseau idealizou para o processo educacional/formativo de seu aluno Emílio, que deveria se aproximar de forma verdadeira, e não hipócrita e dissimuladamente, de suas disposições naturais por meio da razão. Mas é justamente essa razão que dá sinais cada vez mais evidentes de esgotamento. E isso ocorre principalmente quando o desejo de se tornar também uma marca, uma propaganda de si próprio, desejo esse que é insuflado pela indústria cultural hodierna, recrudesce tanto o poder do preconceito delirante - tal como nas situações de extermínio dos "diferentes" que não compactuam com o gosto de um mesmo time de futebol ou de música, ou nos pátios das escolas onde os alunos humilham aqueles que não portam determinados logotipos em suas vestimentas - quanto do sadismo do aluno que se vinga da dor 
masoquistamente reprimida por meio de sua inserção nas comunidades virtuais da internet. $\mathrm{O}$ atual indivíduo semiformado encontra, no espaço virtual, a possibilidade de concretizar o anseio de manifestar seu descontentamento com os professores, na medida em que temas tabus, tal como a queixa da soberba professoral, são explicitamente colocados, pois os gritos das letras garrafais de tais comunidades têm o poder de romper o silêncio que prevalecera durante das situações de humilhação as quais foram submetidos no transcorrer do cotidiano escolar.

De todo modo, tais comunidades virtuais poderiam ser um "locus" no qual os alunos seriam "ouvidos" por seus professores, suscitando assim o surgimento de uma relação dialógica cujos efeitos pedagógicos se espraiariam também para as relações presenciais entre professores e alunos. Novos e progressivos avatares, para se fazer uso de uma expressão atual, poderiam ser produzidos entre tais agentes educacionais, de tal maneira que a comunicação secundária, não presencial, incentivaria o incremento da comunicação primária, presencial. E se ainda pulsa a promessa de que o desenvolvimento científico e tecnológico, na condição de conquista da humanidade, poderia contribuir para abrandar o cansaço físico e mental, é necessária a reflexão crítica sobre o modo como as atuais relações de produção revitalizam o processo semiformativo e a frialdade entre as pessoas. No atual momento, essas mesmas relações de produção apartam cada vez mais do consciente a possibilidade deste desenvolvimento ajudar a fomentar a existência de uma vida mais dignamente humana, ao mesmo tempo em que nos aproximamos, sob a influência de novos véus tecnologicos, da reincidência de práticas afeitas às barbáries cometidas em Auschwitz.

\section{Referências}

ADORNO, T. W. Erziehung nach Auschwitz. In: . Erziehung zur Mündigkeit. Frankfurt am Main: Suhrkamp Verlag. 1971. ; HORKHEIMER, M. Dialética do esclarecimento: fragmentos filosóficos. Tradução de Guido Antonio de Almeida. Rio de Janeiro: Zahar. 1986. 
. Teoria da Semicultura. Tradução de Newton Ramos de Oliveira, Bruno Pucci e Claudia B. Abreu. Educação \& Sociedade (Cedes), Campinas, ano XVII, v. 56. p. 388-411, Dez. 1996.

ANDERS, G. Die Antiquiertheit des Menschen I. München: C. H. Beck. 2002.

BRECHT, B. A vida de Galileu. Tradução de Roberto Schwartz. São Paulo: Abril. 1977.

DEBORD, G. A Sociedade do espetáculo. Tradução de Estela dos Santos Abreu. Rio de Janeiro: Contraponto. 1997.

FREIRE, P. Pedagogia do oprimido. Rio de Janeiro: Paz e Terra. 1978.

FLUSSER, V. O Universo das imagens técnicas: elogio da superficialidade. São Paulo: Annablume. 2008.

SANTOS, L. G. dos Politizar as novas tecnologias: o impacto sóciotécnico da informação digital e genética. São Paulo: editora 34. 2003.

GRUSCHKA, A. Bürgeliche Kälte und Pädagogik. Wetzlar: Büsche der Pandora. 1994.

HELLMANN, K. U. Soziologie der Marke. Frankfurt am Main: Suhrkamp Verlag. 2003.

KLEIN, N. Sem logo: a tirania da marcas em um planeta vendido. Tradução de Ryta Vinagre. Rio de Janeiro; São Paulo: Record. 2003.

MARX, K.; ENGELS, F. O manifesto comunista. Tradução de Maria Lucia Como. São Paulo: Paz e Terra. 1998.

NIETZSCHE, F. Genealogia da moral. Tradução de Paulo César de Souza. São Paulo: Companhia das Letras. 1998.

HORKHEIMER, M. Teoria tradicional e teoria critica. Coleção: Os Pensadores. Tradução de Edgar Afonso Malagodi e Ronaldo Pereira Cunha. São Paulo: Abril. 1991.

LEVI, P. Se questo è un uomo - La tregua. Torino: Einaudi editore. 1989. POE, E. A. The man of the crowd. In: STERN, V. D. (Org.). The portable Poe. New York: Penguin books. 1977. 
POSTMAN, N. O desaparecimento da infância. Tradução de Suzana Menescal de A. Carvalho e José Laurenio de Melo. Rio de Janeiro: Graphia. 1999.

QUINTANA, M. Caderno H. Rio de Janeiro: Editora Globo. 1983.

ROUSSEAU, J. J. Emílio ou da educação. Tradução de Sérgio Milliet. Rio de Janeiro: Editora Bertrand Brasil. 1992.

TÜRCKE, C. Erregte Gesellschaft: Philosophie der Sensation. München: C. H. Beck. 2002.

Data de registro: 05/01/2010 Data de aceite: 20/05/2010 